\title{
EFEITO DA COMPLEXIDADE EMPRESARIAL NO GERENCIAMENTO DE RESULTADOS DE EMPRESAS BRASILEIRAS
}

\author{
Alini da Silva 1 \\ Roberto Carlos Klann 2
}

- Artigo recebido em: 20/12/2016 •- Artigo aceito em: 22/05/2018 -.- Segunda versão aceita em: 13/08/2018

\section{RESUMO}

O objetivo do estudo foi analisar o efeito da complexidade empresarial no gerenciamento de resultados de empresas brasileiras. A metodologia pode ser caracterizada como descritiva, documental e quantitativa. A amostra foi composta por 110 empresas listadas na B3, no período compreendido entre os anos de 2010 a 2013. A coleta de dados foi realizada pela base de dados Thomson, formulários de referências das empresas, notas explicativas e dados cadastrais. Para a análise dos dados utilizou-se de técnicas estatísticas, tais como: regressão linear múltipla, estatística descritiva, entropia da informação, método TOPSIS e regressão de dados em painel, por meio dos softwares SPSS e STATA. Os resultados demonstraram que a experiência de mercado das empresas e a rentabilidade do patrimônio líquido aumentaram o nível de gerenciamento de resultados das empresas analisadas. Por outro lado, as dívidas de longo prazo e a complexidade total auxiliaram na redução desta prática oportunista dos gestores. Conclui-se que a complexidade de empresas aumenta a prática oportunista de gestores, quando na empesa apresentam-se formas de complexidade de forma individualizada, mas também pode contribuir para a sua diminuição, principalmente quando a empresa possui de forma conjunta várias medidas de complexidade.

Palavras-Chave: Complexidade industrial. Complexidade do negócio. Complexidade organizacional. Gerenciamento de resultados.

\footnotetext{
1 Doutora em Ciências Contábeis e Administração, Universidade Regional de Blumenau, Programa de Pós-Graduação em Ciências Contábeis, PPGCC sala D-202 - Campus I, Universidade Regional de Blumenau. Endereço: Rua Antônio da Veiga, 140 - Bairro Itoupava Seca, 89030-903. Blumenau-SC. E-mail: alinicont@gmail.com.

https://orcid.org/0000-0002-7043-5566

2 Doutor em Ciências Contábeis e Administração, Universidade Regional de Blumenau, Programa de Pós-Graduação em Ciências Contábeis, PPGCC sala D-202 - Campus I, Universidade Regional de Blumenau. Endereço: Rua Antônio da Veiga, 140 - Bairro Itoupava Seca, 89030-903, Blumenau-SC. E-mail: rklann@furb.br.

https://orcid.org/0000-0002-3498-0938
} 


\title{
EFFECT OF COMPLEX IN BUSINESS MANAGEMENT BRAZILIAN RESULTS
}

\begin{abstract}
The aim of the study was to analyze the effect of business complexity in managing results of Brazilian companies. The methodology can be characterized as descriptive, document and quantitative. The sample consisted of 110 companies listed on B3, in the period between the years 2010 to 2013. The data collection was conducted by Thomson database, forms of references of companies, notes and record data. For data analysis was used statistical techniques such as multiple linear regression, descriptive statistics, information entropy, TOPSIS method and panel data regression through SPSS and STATA. The results showed that the market experiences of businesses and the profitability of equity increased earnings management level of the companies analyzed. On the other hand, long-term debt and total complexity helped to reduce this opportunistic practice managers. It is concluded that the complexity of business increases the opportunistic practice managers when in Empesa we present forms of complexity individually, but can also contribute to their reduction, especially when the company has jointly various measures of complexity.
\end{abstract}

Keywords: Industrial complexity. Complexity of business. Organizational complexity. Results management.

\section{INTRODUÇÃO}

A prática de gerenciamento de resultados, de acordo com Martinez (2006), é tema contábil crítico e contemporâneo, o qual tem sido amplamente discutido no meio acadêmico internacional e nacional, visto o efeito que possui no mercado de capitais, caso esta prática comprometa as decisões dos usuários. A prática refere-se a uma intervenção intencional em relatórios financeiros, a fim da obtenção de ganhos particulares (Schipper, 1989). Gestores utilizam de seu julgamento para manipular contas contábeis discricionárias em relatórios, com o intuito de reportar resultados econômico-financeiros da empresa ao mercado de capitais, de acordo com seus interesses (Dechow, Sloan \& Sweeney, 1995; Healy \& Whalen, 1999).

Pesquisas sobre a prática oportunista de gestores investigaram os fatores que impactam administradores a manipular os lucros contábeis, bem como as consequências deste comportamento e como o realizam (Mcnichols, 2000). Segundo Dechow, Ge e Schrand (2010), a literatura necessita de mais pesquisas sobre os fatores que influenciam a qualidade da informação contábil, identificando as fontes potenciais de distorções que afetam o sistema de contabilidade, o desempenho financeiro empresarial e as informações divulgadas.

O gerenciamento de resultados pode ser impactado por diferentes fatores, tais como: mudanças em métodos utilizados na contabilidade, alteração na estrutura de capital (Jones, 1991) e aplicação de novas normas contábeis. Segundo Leuz (2003) e Lopes (2009), há fatores específicos das empresas, como características particulares e diferenciadas, que também podem influenciar a qualidade dos relatórios contábeis, as quais merecem ser objeto de investigação.

2 Revista Contabilidade Vista \& Revista, ISSN 0103-734X, Universidade Federal de Minas Gerais, Belo Horizonte, v. 31, n. 1, p. 1-28, jan./abr. 2020 
Tais características específicas relacionam-se com fatores institucionais, como a concentração de propriedade e a complexidade de empresas.

A complexidade de empresas refere-se a atividades, características ou fenômenos organizacionais que contrariam o paradigma da simplicidade (Santos \& Rodrigues, 2007), diferenciando-se em complexidade do negócio, complexidade da indústria, complexidade organizacional, complexidade geográfica, complexidade de estrutura de custos e complexidade total. A complexidade de empresas, de acordo com Anderson (1999), pode estar associada com a redução da simetria informacional entre os agentes econômicos e à dissimulação do desempenho organizacional.

A diversificação em determinada atividade operacional (característica de empresas complexas), pode impactar a assimetria da informação entre gestores e agentes econômicos. Gestores de empresas complexas, com maior quantidade de segmentos de atuação, número de subsidiárias e concentração industrial, tendem a ter maior poder e prestígio, o que favorece a manipulação de contas contábeis para a efetivação de benefícios pessoais.

De acordo com Cetorelli e Goldberg (2014), as empresas complexas possuem a tendência de apresentar estratégias de gestão, opções de financiamento, políticas de liquidez, bem como decisões sobre investimento diferentes em comparação com empresas pouco complexas. Estudos internacionais investigaram a complexidade de empresas e o comportamento oportunista de gestores. Farooqi, Harris e Ngo (2014) apontaram que a complexidade diminui tal comportamento e, dessa forma, contribui para a melhoria na qualidade da informação contábil, enquanto que estudos como Demirkan, Radhakrishnan e Urcan (2012), Barinov, Park e Yildizhan (2014) e Jennings e Tanlu (2014) apontaram o inverso, ou seja, que a complexidade de empresas prejudica a qualidade da informação contábil.

Assim, depreende-se que empresas que possuem complexidade em suas atividades estão propensas ao oportunismo de gestores, em que estes, a fim de obterem benefícios pessoais, reduzem a riqueza dos acionistas e causam custos de agência (Denis, Denis \& Sarin, 1997). A Teoria da Agência pressupõe que gerentes de empresas diversificadas (complexas), tendem a manipular decisões, com o intuito de aumentar sua remuneração, poder e prestígio, ao considerar o poder discricionário que detêm em atividades operacionais (Farooqi, Harris \& Ngo, 2014).

Além disso, os processos de negócios de empresas altamente complexas estão mais propensos a erros do que as demais empresas, visto que as atividades complexas são de difícil entendimento e, por consequência, exigem maior controle por parte dos gestores, caso contrário pode-se agravar a assimetria da informação (Muketha, Ghani, Selamat \& Atan, 2010). A complexidade de empresas limita a transparência de informações empresariais ao mercado, acarretando assimetria informacional, visto a diversificação em determinadas atividades (Liu \& Lai, 2012).

Há estudos que analisaram o efeito da complexidade no gerenciamento de resultados de empresas dos EUA (Bushman, Chen, Engel \& Smith, 2004; Demirkan et al., 2012; Jennings \& Tanlu, 2014), Geórgia (Barinov et al., 2014) e França (Farooqi et al., 2014), tornando-se- oportuna a investigação em demais cenários econômicos, como o caso de empresas brasileiras, as quais estão inseridas em 
um mercado emergente com características particulares em relação a esses países (taxa de inflação alterada, menor desenvolvimento econômico e investimentos externos), contribuindo para o aprofundamento do tema.

Diante das ponderações sobre a relação entre a complexidade de empresas e a prática oportunista de gestores, apresenta-se a seguinte questão problema: qual o efeito da complexidade empresarial na prática de gerenciamento de resultados de empresas brasileiras? Com 0 intuito de responder a esta questão, têm-se como objetivo avaliar o efeito da complexidade empresarial na prática de gerenciamento de resultados de empresas brasileiras.

A literatura aponta diversas pesquisas internacionais sobre a relação entre medidas de complexidade e o comportamento oportunista de gestores em mercados desenvolvidos (Demirkan et al., 2012; Jennings \& Tanlu; 2014; Barinov et al., 2014; Farooqi et al., 2014). No entanto, há uma lacuna de pesquisa quanto à investigação deste problema em demais cenários econômicos, como em mercados em desenvolvimento, caso de empresas brasileiras.

Observam-se como lacuna de pesquisa também as métricas utilizadas para detectar a complexidade de empresas e a prática oportunista de gestores. Os estudos têm utilizado diversos modelos para a verificação do gerenciamento de resultados, porém, não observaram os modelos Jones Modificado - Dechow et al. (1995) e Kang e Silvaramakrishnan -KS (1995), os quais são utilizados no presente estudo. Utilizou-se o Modelo Jones Modificado para a análise principal do trabalho, enquanto o Modelo KS proporcionou análise de sensibilidade dos dados.

A utilização de diferentes métricas para se verificar a complexidade de empresas e o gerenciamento de resultados contribui para a expansão e o aprofundamento dos resultados, fornecendo uma visão mais ampla a respeito da influência da complexidade sobre as práticas de gerenciamento de resultados. Empresas podem ser complexas sob diversas características, assim, esta pesquisa busca verificar a complexidade empresarial (total das empresas), a qual abrange a complexidade industrial, do negócio e organizacional, não limitando a análise em somente um aspecto de diversificação empresarial. Da mesma forma, a utilização dos modelos Jones Modificado e KS para a detecção do gerenciamento de resultados deve-se ao fato de que cada modelo abrange um grupo de informações diferenciadas (Dechow et al., 1995; Thomas \& Zhang, 2000; Martinez, 2008). Também, neste estudo formulou-se um índice de complexidade total (empresarial), com base nas medidas de complexidade industrial, do negócio e organizacional.

Os resultados fornecem informações importantes a órgãos reguladores, normatizadores, auditores e preparadores das demonstrações contábeis, para a formulação de normas contábeis, de governança e controles específicos para as empresas que possuem determinadas características de complexidade, a fim de mitigar a prática oportunista de gestores, auxiliando na melhora da qualidade da informação contábil. 


\section{COMPLEXIDADE EMPRESARIAL E ASSIMETRIA DA INFORMAÇÃO}

A diversificação de empresas foi pesquisada inicialmente por estudiosos da economia industrial e de organizações, economia financeira, teoria da organização, marketing e gestão estratégica (Ramanujam \& Varadarajan, 1989). Nos últimos anos, a "diversificação de empresas" vem sendo estudada como "complexidade de empresas" em contabilidade financeira (Demirkan et al., 2012; Farooqi et al., 2014), bem como seus efeitos na assimetria da informação.

Dentre os estudos de complexidade de empresas relacionados à assimetria informacional, observaram-se diferentes métricas para a verificação de complexidade, tais como: número de segmentos (Demirkan et al., 2012; Barinov; et al., 2014), geográfica (Bushman et al., 2004; Liu \& Lai, 2012; Cetorelli \& Goldberg, 2014) e industrial (Bushman et al., 2004; Liu \& Lai, 2012; Farooqi et al., 2014; Barinov et al., 2014).

No presente estudo utilizou-se três medidas de complexidade de empresas: a) a industrial, medida pelo índice Herfindahl (Barinov et al., 2014); b) do negócio, medida pela quantidade de segmentos em que a empresa atua (Demirkan et al., 2012; Barinov et al., 2014; Cetorelli \& Goldberg, 2014; Jennings \& Tanlu, 2014); e c) organizacional, observada pela quantidade de subsidiárias (Cetorelli \& Goldberg, 2014), tamanho, idade da empresa, rentabilidade, estrutura de capital e dívidas de longo prazo (Farias, 2012).

O índice Herfindahl utilizado para captar a complexidade industrial, de acordo com Barinov et al. (2014), é uma extensão do indicador utilizado por Bushman et al. (2004), com o acréscimo somente do número 1 (um) na fórmula, o qual tem por intuito estabelecer que o índice varia de 0 a 1 . Assim, quanto mais próximo de 1 o índice, maior a complexidade. Este índice é calculado pela relação das vendas de cada segmento em que a empresa atua com as vendas totais da empresa (Hou \& Robinson, 2006; Barinov et al., 2014), o qual captura a concentração da indústria e vem sendo utilizado por autores de complexidade (Liu \& Lai, 2012; Farooqi et al., 2014; Barinov et al., 2014) para retratar a complexidade industrial.

A complexidade do negócio pode ser verificada pela quantidade de segmentos em que a empresa atua (Boone, Field, Karpoff \& Raheja, 2007; Doyle, Ge \& Mcvay, 2007; Demirkan et al., 2012; Farias, 2012; Cetorelli \& Goldberg, 2014; Jennings \& Tanlu, 2014; Barinov et al., 2014), que representa a diversificação de áreas de atuação. Empresas que competem em vários setores, por exercer atividade em ambiente informativo e operacional complexo, tendem a desembolsar elevados custos de monitoramento, a fim de diminuir a assimetria informacional (Bushman et al., 2004).

A complexidade organizacional é uma medida padrão para a medição de complexidade de empresas, verificada pela soma de todas as subsidiárias da empresa que satisfaçam critérios de propriedade. Considera-se a quantidade de subsidiárias como métrica de complexidade organizacional, em que pelo menos a empresa sede detêm $50 \%$ da propriedade das subsidiárias. Esta medida é relevante por retratar a fragmentação organizacional (Cetorelli \& Goldberg, 2014). De acordo com Farias (2012), a complexidade organizacional pode, além de outras medidas (subsidiárias), ser avaliada também, pelo tamanho e anos de 
atuação da empresa, dívida de longo prazo, estrutura de capital e rentabilidade que apresenta.

O tamanho da empresa é considerado como medida de complexidade organizacional, pois retrata a extensão da organização em termos de ativos, o que representa elevada diversificação de seus bens e direitos. Processos complexos elevam o tamanho da organização (Fama \& Jensen, 1983; Boone et al., 2007; Linck, Netter \& Yang, 2008). A idade da empresa como medida de complexidade organizacional (Boone et al., 2007; Farias, 2012) representa o ciclo de vida das organizações, sua flexibilidade no mercado e controle das atividades organizacionais, que garantem a permanência de suas atividades (Santos \& Rodrigues, 2007). A complexidade aumenta com a idade da empresa (Linck et al., 2008).

As dívidas de longo prazo e a concentração de capital de terceiros na estrutura de capital representam medidas de complexidade organizacional (Linck et al., 2008; Farias, 2012) ao retratarem a complexidade financeira da empresa. A rentabilidade das empresas também é considerada como medida de complexidade organizacional (Farias, 2012), a qual informa a diversificação do lucro e da produção (Cardinaels, Roodhooft \& Warlop, 2004).

A qualidade da informação contábil em empresas com complexidade industrial, de acordo com Bushman et al. (2004) e Demirkan et al. (2012), é prejudicada principalmente em função de contas como provisões e estimativas, que impactam o lucro das empresas e que necessitam de julgamento de profissionais. Empresas complexas industrialmente divulgam informações limitadas a seu segmento principal de atuação, implicando em assimetria da informação com os investidores externos (Liu \& Lai, 2012). Gestores diversificam (tornam complexas) empresas industrialmente, em organizações que disponibilizam fracos direitos aos acionistas, explorando os direitos destes e gerando problemas de agência (Jiraporn, Kim, Davidson \& Singh, 2006). Diante destas considerações, apresenta-se a primeira hipótese de pesquisa.

$H_{1}$ : quanto maior o grau de complexidade industrial, maior a prática de gerenciamento de resultados das empresas.

Empresas que competem em vários setores, por exercerem atividades em ambiente informativo e operacional complexo, apresentam assimetria informacional, com a tendência de desembolsar elevados custos de monitoramento (Martin \& Sayrak, 2003; Bushman et al., 2004; Jiraporn et al., 2006). A qualidade de acumulações discricionárias e o custo de capital entre empresas que atuam em um único segmento em comparação com aquelas que atuam em vários segmentos são diferenciados, visto que as atuantes em vários segmentos apresentam maiores problemas de agência, diminuindo, dessa forma, a qualidade da informação contábil (Demirkan et al., 2012).

Para analisar o impacto da complexidade do negócio na assimetria da informação, Demirkan et al. (2012) utilizaram as acumulações discricionárias, verificando que a complexidade do negócio aumentou a assimetria informacional. Com base nestes argumentos, apresenta-se a segunda hipótese do estudo, que relaciona a complexidade do negócio com assimetria da informação, em que a assimetria é analisada sob a perspectiva do gerenciamento de resultados. 
$\mathrm{H}_{2}$ : quanto maior o grau de complexidade do negócio, maior a prática de gerenciamento de resultados das empresas.

As medidas de complexidade organizacional quantidade de subsidiárias e rentabilidade da empresa tendem a associar-se com maior gerenciamento de resultados. Empresas que possuem maior número de subsidiárias podem apresentar distância cultural e centralização de controle, resultando em assimetria de informação entre as subsidiárias e sua sede, além de maior discricionariedade administrativa (Roth \& O'donnell, 1996).

Quanto à rentabilidade da empresa, de acordo com Baptista (2008), gestores gerenciam o resultado para aumentá-lo, com o intuito de evitar decréscimo da rentabilidade empresarial. Os gestores exploram e manipulam resultados em organizações com complexidade organizacional devido a maior dimensão e complexidade das atividades da empresa, ocasionando conflitos de agência e aumento da assimetria (Farooqi et al., 2014).

Por outro lado, algumas características ou variáveis complexas do contexto operacional e informacional das empresas interferem no comportamento discricionário dos agentes, por apresentar influência nos mecanismos de incentivos e de monitoramento para o controle de seu comportamento (Farias, 2012). O tamanho da empresa, o seu tempo de atuação/existência, as dívidas de longo prazo e a sua estrutura de capital (que são também medidas de complexidade organizacional) associam-se com $\circ$ menor nível de gerenciamento de resultados. Empresas com grande volume de ativos (Baptista, 2008) e com períodos longos de atuação no mercado (Chichernea, Holder \& Wei, 2012) são mais preparadas para a realização de estimativas, especializadas e com mecanismos robustos para detectar irregularidades, contribuindo para a melhora da qualidade da informação contábil.

Saldos maiores de dívidas de longo prazo e concentração elevada de capital de terceiros na estrutura de capital associam-se com a redução do gerenciamento de resultados. A qualidade da informação contábil beneficia a captação de recursos de terceiros, por transmitir fidedignamente as informações financeiras aos credores. Em contrapartida, os agentes econômicos oferecem recursos a custos menores, o que alavanca as dívidas de longo prazo e capitais de terceiros na estrutura de capital da empresa (Hail \& Leuz, 2009). Com base no exposto, apresenta-se a terceira hipótese de pesquisa e suas sub-hipóteses:

$H_{3}$ : as medidas de complexidade organizacional apresentam influência significativa na prática de gerenciamento de resultados das empresas.

$H_{3 a}$ : quanto maior a quantidade de subsidiárias, maior a prática de gerenciamento de resultados das empresas.

$H_{3 b}$ : quanto maior a rentabilidade, maior a prática de gerenciamento de resultados das empresas.

$H_{3 c}$ : quanto maior o tamanho, menor a prática de gerenciamento de resultados das empresas.

$H_{3 d}$ : quanto maior o tempo de atuação no mercado, menor a prática de gerenciamento de resultados das empresas.

$H_{3 e}$ : quanto maior o saldo das dívidas de longo prazo, menor a prática de gerenciamento de resultados das empresas. 
$H_{3 f}:$ quanto maior a concentração de capital de terceiros na estrutura de capital, menor a prática de gerenciamento de resultados das empresas.

O efeito individual de uma medida de complexidade na assimetria de informação pode ser diferente em relação ao comportamento de um conjunto de tais medidas (Liu \& Lai, 2012; Farooqi et al., 2014). De acordo com Farooqi et al. (2014), a complexidade global causa menos problemas de agência nas empresas do que a complexidade industrial, por exemplo.

Empresas que apresentam várias medidas de complexidade podem ter menos assimetria de informação do que àquelas com somente uma medida de complexidade, ao considerar que uma empresa complexa globalmente possui mais mecanismos de controle das informações em comparação àquelas que começaram a diversificar suas atividades. Para capturar esse efeito global da complexidade, desenvolveu-se uma proxy de complexidade total (baseado nas medidas de complexidade industrial, do negócio e organizacional) e formulou-se a quarta última hipótese da pesquisa.

$H_{4}$ : a existência conjunta de complexidade industrial, do negócio e organizacional implica em menores práticas de gerenciamento de resultados.

A confirmação da $\mathrm{H}_{1}$ e $\mathrm{H}_{2}$ indicará que empresas com faturamento menos concentrado em poucos setores e que operam em diversos segmentos estão mais propensas a se envolverem em práticas de gerenciamento de resultados. Caso $\mathrm{a} \mathrm{H}_{3}$ seja confirmada, poderá se verificar a assertiva de que empresas com maior número de subsidiárias e de maior rentabilidade se envolvem mais em gerenciamento de resultados, enquanto empresas maiores, com elevado tempo de atuação no mercado, com concentração de capital de terceiros na estrutura de capital e saldos elevados de dívidas de longo prazo possuem menores práticas de gerenciamento de resultados. Em relação à hipótese $\mathrm{H}_{4}$, caso esta seja confirmada, indicará que empresas com complexidade total, ou seja, empresas que apresentem em conjunto complexidade industrial, do negócio e organizacional, são menos propensas a práticas de gerenciamento de resultados.

\section{MÉTODO E PROCEDIMENTOS DA PESQUISA}

Os procedimentos metodológicos definem-se por descritivo, documental e quantitativo. A população do estudo compõe-se por todas as empresas listadas na B3 - Brasil, Bolsa e Balcão. A B3 é fruto da combinação entre a BM\&FBOVESPA e a Cetip, formando uma empresa de infraestrutura de mercado financeiro de classe mundial (B3, 2018).

A amostra foi constituída por 110 empresas, as quais dispunham de todas as informações necessárias para a realização da pesquisa. Para tal, considerou-se as empresas com informações válidas em todas as observações (variáveis e períodos analisados). Inicialmente, para se verificar o efeito da complexidade empresarial no gerenciamento de resultados, calculou-se o nível de gerenciamento de resultados das empresas, com base no Modelo Jones Modificado - Modelo de Dechow et al. (1995), o qual pode ser observado pela Equação 1. 
Modelo Jones Modificado

$\mathrm{TA}_{\mathrm{it}}=\varphi_{0}+\varphi_{1}\left[\Delta \mathrm{ReV}_{\mathrm{it}}-\Delta \mathrm{Rec}_{\mathrm{it}}\right]+\varphi_{2} \mathrm{PPE}_{\mathrm{i \dagger}}+\varepsilon_{i \dagger}$

Onde:

$\mathrm{TA}_{\text {it }}=$ accruals totais da empresa i no ano $\mathrm{t}$, calculadas pelo enfoque do Balanço;

$\triangle R E V=$ receita no ano $t$ menos receita no ano $t-1$ para a empresa $i$;

$\triangle R E C=$ são as contas líquidas a receber no ano $\dagger$ menos as contas líquidas a receber no ano t-1 para a empresa i;

$\mathrm{PPE}_{i \dagger}=$ ativo imobilizado bruto no ano $t$ para a empresa $\mathrm{i}$;

$\varepsilon_{\text {it }}=$ termo de erro no ano $\dagger$ para a empresa i (proxy de gerenciamento).

Com base nos accruals discricionários (gerados pelos resíduos da regressão), foram elaboradas novas equações, utilizando-se como variáveis dependentes os accruals do Modelo Jones Modificado e como variáveis independentes as medidas de complexidade, além de variáveis de controle. Na Figura 1 pode-se observar o constructo da pesquisa. 


\begin{tabular}{|c|c|c|c|c|c|}
\hline $\begin{array}{l}\text { Tipo de } \\
\text { Variável }\end{array}$ & Dimensão & Variável & Descrição & Fórmula & Autores \\
\hline \multirow{3}{*}{$\begin{array}{l}\mathscr{0} \\
\frac{1}{c} \\
\frac{1}{0} \\
0 \\
\frac{c}{0} \\
0 \\
0 \\
0\end{array}$} & \multirow{3}{*}{ 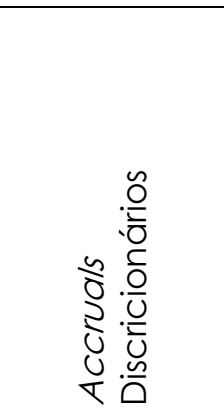 } & ADMJM & $\begin{array}{l}\text { Accruals Discricionários (AD) } \\
\text { por módulo (M) do Jones } \\
\text { Modificado (JM) }\end{array}$ & \multirow{3}{*}{ Não se aplica } & \multirow{3}{*}{ Não se aplica } \\
\hline & & ADPJM & $\begin{array}{l}\text { Accruals Discricionários (AD) } \\
\text { positivos (P) do Jones } \\
\text { Modificado (JM) }\end{array}$ & & \\
\hline & & ADNJM & $\begin{array}{l}\text { Accruals Discricionários (AD) } \\
\text { negativos (N) do Jones } \\
\text { Modificado (JM) }\end{array}$ & & \\
\hline \multirow{8}{*}{ 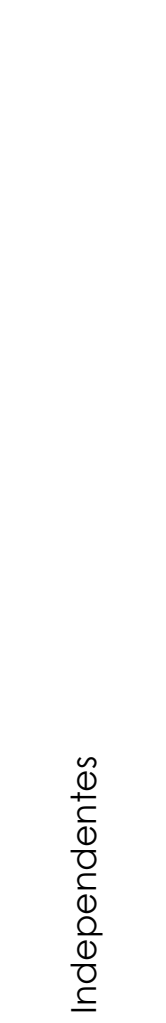 } & 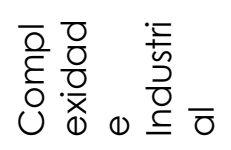 & $\begin{array}{l}\text { Complexidade } \\
\text { Industrial } \\
\text { (Cl) }\end{array}$ & $\begin{array}{l}\text { Índice Herfindahl: } \\
\text { HHI é o índice Herfindahl }\end{array}$ & $\begin{array}{l}1-(\mathrm{HHI}= \\
\left.\sum \mathrm{N}_{\mathrm{i}=1} \mathrm{Si}^{2}\right)\end{array}$ & Barinov et al. (2014) \\
\hline & 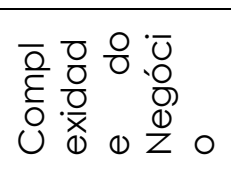 & $\begin{array}{l}\text { Complexidade } \\
\text { Negócio }(\mathrm{CN})\end{array}$ & $\begin{array}{l}\text { Medido pela quantidade de } \\
\text { segmentos em que a empresa } \\
\text { participa. }\end{array}$ & Não se aplica. & $\begin{array}{l}\text { Demirkan, et al. (2012); } \\
\text { Barinov, et al. (2014), } \\
\text { Cetorelli e Goldberg, (2014), } \\
\text { Jennings e Tanlu (2014). }\end{array}$ \\
\hline & \multirow{6}{*}{ 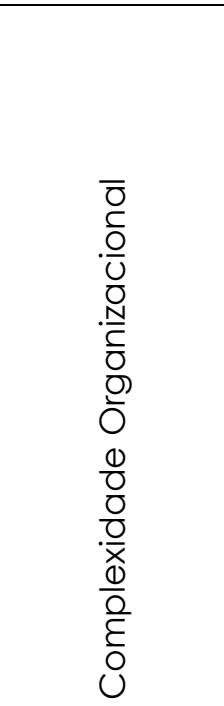 } & $\begin{array}{l}\text { Número de Subsidiárias } \\
\text { (SUB) }\end{array}$ & $\begin{array}{l}\text { Número de subsidiárias da } \\
\text { empresa. }\end{array}$ & Não se aplica. & Cetorelli e Goldberg (2014) \\
\hline & & $\begin{array}{l}\text { Anos de atuação da } \\
\text { empresa (AA) }\end{array}$ & $\begin{array}{l}\text { Quantidade de anos que a } \\
\text { empresa opera no mercado. }\end{array}$ & Não se aplica. & $\begin{array}{l}\text { Doyle et al. (2007), Boone et } \\
\text { al. (2007), Chichernea et al. } \\
\text { (2012), Farias (2012). }\end{array}$ \\
\hline & & $\begin{array}{l}\text { Tamanho da empresa } \\
\text { (TAM) }\end{array}$ & $\begin{array}{l}\text { Logaritmo natural do ativo } \\
\text { total da empresa. }\end{array}$ & Não se aplica. & $\begin{array}{l}\text { Leuz (2003), Doyle et al. } \\
\text { (2007), Baptista (2008), } \\
\text { Farias (2012). }\end{array}$ \\
\hline & & Rentabilidade (ROE) & $\begin{array}{l}\text { Rentabilidade do patrimônio } \\
\text { líquido (PL) }\end{array}$ & Lucro Líquido / PL & $\begin{array}{l}\text { Doyle et al. (2007), Baptista } \\
\text { (2008), Farias (2012). }\end{array}$ \\
\hline & & $\begin{array}{l}\text { Dívidas de longo prazo } \\
\text { (DLP) }\end{array}$ & $\begin{array}{l}\text { Logaritmo natural do saldo } \\
\text { das dívidas de longo prazo. }\end{array}$ & Não se aplica. & $\begin{array}{l}\text { Bushman et al. (2004), Farias } \\
\text { (2012). }\end{array}$ \\
\hline & & Estrutura de capital (EC) & $\begin{array}{l}\text { Relação entre Passivo Total e } \\
\text { Patrimônio Líquido ao final do } \\
\text { período }\end{array}$ & Passivo Total / PL & Farias (2012). \\
\hline
\end{tabular}


Efeito da Complexidade Empresarial no Gerenciamento de Resultados de Empresas Brasileiras

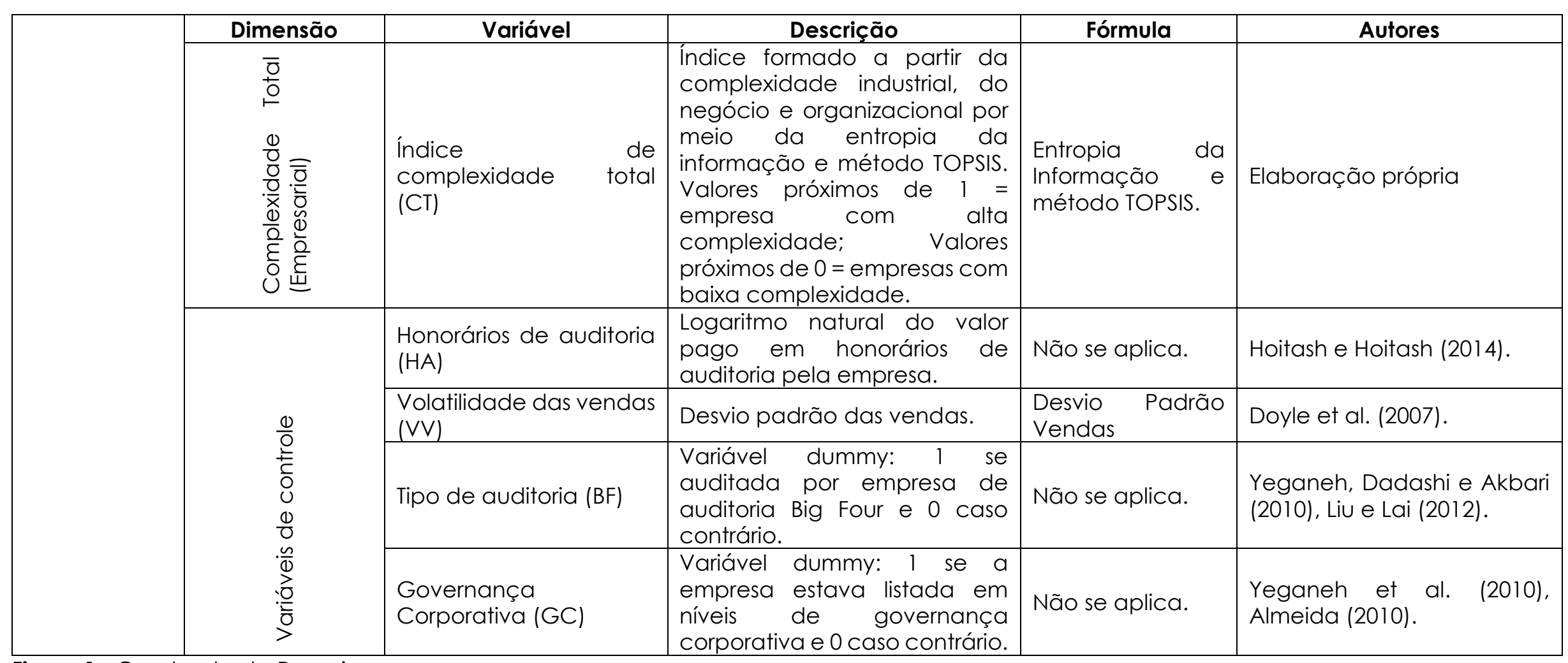

Figura 1 - Constructo da Pesquisa

Fonte: Elaborada pelos autores. 
Com base na Figura 1 observam-se 3 variáveis dependentes. Estas variáveis foram geradas pelos acruals discricionários calculados pelo Modelo Jones Modificado. Foram segregadas as variáveis dependentes em accruals por módulo (ADMJM), accruals negativos (ADNJM) e acrruals positivos (ADPJM). Os accruals foram separados desta forma, pois a influência das variáveis independentes e de controle pode ocorrer de forma diferenciada nos acruals positivos e negativos.

Para a formulação do índice de complexidade total (CT), utilizou-se dos pesos (entropia da informação) das variáveis (complexidade industrial, do negócio e organizacional) para o cálculo do Método de Análise Multicritério TOPSIS, o qual gerou ao final, um índice único de complexidade total (empresarial) para cada empresa analisada.

Com base nas variáveis dependentes de gerenciamento de resultados, independentes de complexidade e as de controle, elaboraram-se 12 equações, as quais se diferenciam pelas três variáveis dependentes de GR e as quatro variáveis de complexidade (industrial, do negócio, organizacional e total), mantendo-se em todas as equações as variáveis de controle. As equações podem ser observadas pela Figura 2.

\begin{tabular}{|c|c|}
\hline Equação & Variáveis \\
\hline 2 & $A D M J M_{i t}=\varphi_{0}+\varphi_{1} C_{l i t}+\varphi_{2} H_{i t}+\varphi_{3} V V_{i t}+\varphi_{4} B_{i t}+\varphi_{5} G_{C i t}+\varepsilon_{i t}$ \\
\hline 3 & ADPJMit $=\varphi_{0}+\varphi_{1} C_{\text {it }}+\varphi_{2} \mathrm{HA}_{i t}+\varphi_{3} V_{V_{i t}}+\varphi_{4} \mathrm{BF}_{i \dagger}+\varphi_{5} \mathrm{GC}_{\text {it }}+\varepsilon_{i t}$ \\
\hline 4 & $A D N J M_{i t}=\varphi_{0}+\varphi_{1} C_{i t}+\varphi_{2} H_{A i t}+\varphi_{3} V_{i t}+\varphi_{4} B_{i t}+\varphi_{5} G_{C i t}+\varepsilon_{i t}$ \\
\hline 5 & $A D M J M_{i t}=\varphi_{0}+\varphi_{1} C N_{i t}+\varphi_{2} H_{A_{i t}}+\varphi_{3} V V_{i t}+\varphi_{4} B_{F_{i t}}+\varphi_{5} G_{\text {it }}+\varepsilon_{i t}$ \\
\hline 6 & $A D P J M_{i t}=\varphi_{0}+\varphi_{1} C N_{i t}+\varphi_{2} H A_{i t}+\varphi_{3} V V_{i t}+\varphi_{4} B_{i t}+\varphi_{5} G_{\text {it }}+\varepsilon_{i t}$ \\
\hline 7 & $A D N J M_{i t}=\varphi_{0}+\varphi_{1} C N_{i t}+\varphi_{2} H A_{i t}+\varphi_{3} V V_{i t}+\varphi_{4} B_{i t}+\varphi_{5} G_{i t}+\varepsilon_{i t}$ \\
\hline 8 & 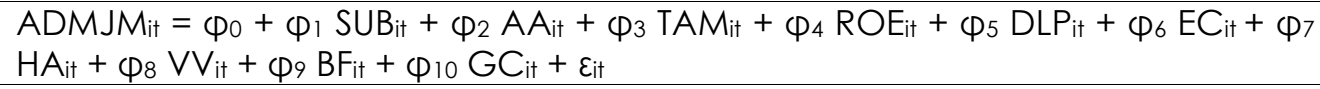 \\
\hline 9 & 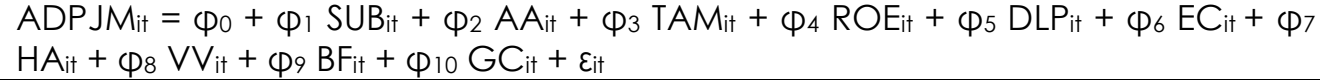 \\
\hline 10 & $\begin{array}{l}A D N J M_{i t}=\varphi_{0}+\varphi_{1} S_{B_{i t}}+\varphi_{2} A A_{i t}+\varphi_{3} T_{A M_{i t}}+\varphi_{4} R E_{i t}+\varphi_{5} D L P_{i t}+\varphi_{6} E C_{i t}+\varphi_{7} \\
H A_{i t}+\varphi_{8} V V_{i t}+\varphi_{9} B_{i t}+\varphi_{10} G C_{i t}+\varepsilon_{i t}\end{array}$ \\
\hline 11 & $\mathrm{ADMJM}_{\mathrm{it}}=\varphi_{0}+\varphi_{1} \mathrm{CT}_{\mathrm{it}}+\varphi_{2} \mathrm{HA}_{\mathrm{it}}+\varphi_{3} \mathrm{VV}_{\mathrm{it}}+\varphi_{4} \mathrm{BF}_{\mathrm{it}}+\varphi_{5} \mathrm{GC}_{\text {it }}+\varepsilon_{\text {it }}$ \\
\hline 12 & $A D P J M_{i t}=\varphi_{0}+\varphi_{1} C_{i t}+\varphi_{2} H A_{i t}+\varphi_{3} V_{i t}+\varphi_{4} B_{i t}+\varphi_{5} G_{i t}+\varepsilon_{i t}$ \\
\hline 13 & $A D N J M_{i \dagger}=\varphi_{0}+\varphi_{1} C_{i \dagger}+\varphi_{2} H A_{i \dagger}+\varphi_{3} V V_{i \dagger}+\varphi_{4} B_{i \dagger}+\varphi_{5} G_{i t}+\varepsilon_{i \dagger}$ \\
\hline
\end{tabular}

Figura 2 - Equações da pesquisa

Fonte: Elaborada pelos autores.

De acordo com a Figura 2, observam-se que as equações 2, 3 e 4 referemse à dimensão complexidade industrial, as quais alteraram-se pelas três variáveis dependentes. Da mesma forma, para as demais dimensões, utilizou-se destas três variáveis de GR como dependentes. As equações 5, 6 e 7 referem-se à dimensão complexidade do negócio. As equações de 8, 9 e 10 referem-se à complexidade organizacional e as equações 11, 12 e 13 remetem-se à complexidade total.

Para a coleta de dados utilizou-se de informações econômico-financeiras disponíveis no sítio eletrônico da Thomson ONE Banker, bem como de informações que caracterizaram as empresas, constantes no formulário de referência, notas explicativas e no sítio eletrônico da B3. 
O período de análise compreendeu os anos de 2010 a 2013, perfazendo um total de 440 observações. Optou-se por este período visto que as informações necessárias para a pesquisa e que constavam no formulário de referência possuíam disponibilidade somente a partir do ano de 2010. Para se verificar a influência da complexidade empresarial no nível de GR foi necessária a exclusão de cinco empresas outliers, as quais possuíam informações discrepantes em relação às demais, o que poderia distorcer os resultados.

Para a consecução do objetivo geral, utilizou-se de técnicas estatísticas para a análise dos dados, como regressão linear múltipla, estatística descritiva, entropia da informação, método TOPSIS e regressão de dados em painel. Por meio da regressão linear múltipla se verificou os resíduos, os quais definem as acumulações discricionárias das empresas, utilizadas como variáveis dependentes nos modelos de dados em painel. A Entropia da informação e o Método TOPSIS foram utilizados para a criação do índice de complexidade total (empresarial). Para a utilização da regressão de dados em painel utilizou-se de painel balanceado, visto a intenção de se avaliar a evolução do efeito da complexidade das empresas no GR ao longo do período, levando à utilização das mesmas empresas nos anos analisados.

\section{DESCRIÇÃO E ANÁLISE DOS RESULTADOS}

Esta seção apresenta a análise e interpretação dos resultados. A Tabela 1 evidencia os resultados da estatística descritiva das variáveis do estudo.

Tabela 1

Estatística descritiva das variáveis do estudo no período de 2010 a 2013

\begin{tabular}{|c|c|c|c|c|c|c|}
\hline \multicolumn{2}{|c|}{ Variáveis } & Mínimo & Máximo & Média & Desvio padrão & Coef. Variação \\
\hline \multicolumn{7}{|c|}{ Variáveis de teste } \\
\hline \multicolumn{2}{|c|}{$\mathrm{Cl}$} & 0,000 & 0,737 & 0,274 & 0,245 & 0,060 \\
\hline \multicolumn{2}{|c|}{$\mathrm{CN}$} & 1,000 & 7,000 & 2,545 & 1,454 & 2,115 \\
\hline \multirow{6}{*}{$\mathrm{CO}$} & SUB & 0,000 & 273,000 & 16,064 & 32,857 & 1079,588 \\
\hline & AA & 0,000 & 122,000 & 37,943 & 27,455 & 753,768 \\
\hline & TAM & 3,171 & 12,380 & 8,303 & 1,468 & 2,156 \\
\hline & ROE & $-70,890$ & 68,400 & 12,402 & 13,528 & 183,002 \\
\hline & DLP & $-1,897$ & 10,720 & 6,915 & 1,760 & 3,097 \\
\hline & EC & 0,128 & 15,714 & 1,736 & 1,727 & 2,981 \\
\hline \multicolumn{2}{|l|}{ CT } & 0,000 & 0,182 & 0,012 & 0,018 & 0,000 \\
\hline \multicolumn{7}{|c|}{ Variáveis de controle } \\
\hline \multicolumn{2}{|c|}{$\mathrm{HA}$} & 0,000 & 20,586 & 13,046 & 2,498 & 6,242 \\
\hline \multicolumn{2}{|l|}{ VV } & 0,002 & 276,794 & 9,863 & 22,424 & 502,841 \\
\hline \multicolumn{2}{|c|}{$\mathrm{BF}$} & 0,000 & 1,000 & 0,907 & 0,291 & 0,084 \\
\hline \multicolumn{2}{|c|}{ GC } & 0,000 & 1,000 & 0,738 & 0,440 & 0,194 \\
\hline
\end{tabular}

Legenda: Cl: complexidade industrial; $C N$ : complexidade do negócio; SUB: quantidade de subsidiárias; AA: anos de atuação; TAM: tamanho da empresa; ROE: rentabilidade do patrimônio líquido; DLP: dívidas de longo prazo; EC: capital de terreiros na estrutura de capital; CT: complexidade total; HA: honorários de auditoria; VV: volatilidade das vendas; BG: tipo de auditoria; GC: governança corporativa.

Fonte: Elaborada pelos autores. 
Conforme demonstrado na Tabela 1, pode-se observar que a variável de teste complexidade industrial (Cl), medida pelo índice Herfindahl, apresenta valor máximo de 0,737 e valor mínimo de 0,000. Este indicador representa alta complexidade industrial quando próximo ao valor de 1. A média da complexidade industrial (CI) foi de 0,274, o desvio padrão de 0,245 e coeficiente de variação de 0,060, o que demonstra pouca dispersão dos dados em relação à média. As empresas analisadas possuem complexidade industrial baixa, com índice médio inferior ao ponto central da escala $(0,274$ para 0,5$)$, o que representa a desigualdade de receita nos segmentos atuantes pelas empresas. A complexidade do negócio (CN), representada pela quantidade de setores, demonstrou média em torno de 2 a 3 setores, com desvio padrão de 1,454 e variância de 2,115. A variável de complexidade organizacional é composta por seis subvariáveis: número de subsidiárias (SUB), tempo de atuação (AA), tamanho (TAM) das empresas, rentabilidade do patrimônio líquido (ROE), dívidas de longo prazo (DLP) e estrutura de capital (EC).

As empresas analisadas possuem em média 17 a 18 subsidiárias. 0 desvio padrão de 32,857 e a variância de 1079,588 demonstraram que uma gama de empresas apresentou quantidade de subsidiárias discrepantes em relação à média. Na amostra houve empresas que não apresentaram nenhuma subsidiária, enquanto outras apresentaram o máximo de 273 subsidiárias.

A média do tempo de atuação das empresas foi de 37,943 anos, com desvio padrão de 27,455 e coeficiente de variação de 753,768, o que revela que inúmeras empresas apresentaram valores diferentes em relação à média, variando de 0 anos (primeiro ano de atuação) a 122 anos de atuação. Em relação ao tamanho da empresa (TAM), representado pelo logaritmo natural do ativo total, verificou-se baixo desvio padrão e variância, podendo-se inferir que as empresas possuem tamanho convergente com a média. $O$ desvio padrão da rentabilidade do patrimônio líquido (ROE) demonstrou-se similar ao valor da média, porém, com variância elevada $(183,002)$, o que revela heterogeneidade dos dados de rentabilidade. Cabe destacar que algumas empresas operaram com rentabilidade negativa, significativamente abaixo do valor da média, enquanto outras apresentaram indicadores de rentabilidade bem acima da média.

O logaritmo natural das dívidas de longo prazo (DLP) demonstrou desvio padrão e variância baixa em relação ao valor da média de 6,915, o que significa dados de endividamento de longo prazo convergentes com a média. A estrutura de capital das empresas (EC) é composta, em média, por $70 \%$ de capital de terceiros. O desvio padrão de 1,727 e a variância de 2,981 denotam que uma parcela das empresas analisadas apresentou estrutura de capital com maior dependência de capital de terceiros.

O índice de complexidade total (CT), medido pela entropia da informação e método TOPSIS (com base nos dados de complexidade industrial, do negócio e organizacional), demonstrou que algumas empresas não possuem qualquer indício de complexidade em suas atividades. O máximo de complexidade total foi de 0,182 e a média de 0,012. Infere-se que as empresas analisadas possuem baixa complexidade total, por possuírem baixo nível de complexidade industrial (pouca dispersão de vendas nos segmentos) e do negócio (baixa quantidade de segmentos em que participa), bem como complexidade organizacional. 
Realizada a análise descritiva, apresenta-se na Tabela 2 a tendência dos accruals discricionários (resíduos) do modelo Jones Modificado por período analisado.

\section{Tabela 2}

Accruals discricionários anuais

\begin{tabular}{l|l|l|l|l}
\hline \multirow{2}{*}{ Modelos } & \multicolumn{4}{l}{ Accruals Discricionários (AD) } \\
\cline { 2 - 5 } & 2010 & 2011 & 2012 & 2013 \\
\hline Jones Modificado & 1,75790 & 28,47707 & $-1,86235$ & $-6,55450$ \\
\hline
\end{tabular}

Fonte: Elaborada pelos autores.

Com base na aplicação do índice Nihans aos accruals discricionários, notase na Tabela 2 que no ano de 2010 e 2011 os gestores realizaram, em média, gerenciamento de resultados para aumentar os lucros. Já nos anos de 2012 e 2013 as empresas investigadas, em média, gerenciaram contas contábeis para diminuir o resultado. Dado o exposto, percebeu-se que as empresas analisadas estão gerenciando seus resultados, reportando lucros ou prejuízos que podem não condizer com sua realidade econômica, o que pode prejudicar a avaliação de desempenho destas empresas e impactar a tomada de decisão dos usuários da informação.

\subsection{Análise Multivariada da Influência da Complexidade Empresarial no GR}

Nesta subseção são apresentados os resultados dos dados em painel da influência da complexidade industrial, do negócio, organizacional e total na prática oportunista dos gestores. Para a análise multivariada destas equações, aplicaram-se inicialmente os testes de pressupostos Durbin-Watson, Shapiro-Wilk e Levene. Observou-se que todas as equações atenderam ao preconizado pelos testes, demonstrando que os resíduos são aleatórios em torno de zero, que a sua distribuição é normal e que a variância dos erros é uniforme, respectivamente. Na Tabela 3 apresentam-se os resultados das equações 2, 3 e 4, as quais têm por intuito verificar o efeito da complexidade industrial no nível de GR.

De acordo com a Tabela 3, percebe-se a utilização do efeito aleatório da regressão de dados em painel nas equações 2 e 3 devido à significância estatística a $1 \%(0,0000)$ nos testes de Chow, LM Breusch-Pagan e não significância estatística no teste de Hausman $(0,3166 ; 0,4547$; respectivamente nas equações 2 e 3). Já para a equação 4 utilizou-se do efeito fixo, visto a significância estatística nos três testes (Chow - 0,0000, LM Breusch-Pagan - 0,0000 e Hausman 0,0356). Constatou-se que as equações apresentaram fraco poder de explicação. Em relação à significância das equações, constatou-se que nenhuma das três equações demonstrou-se significativa. Denota-se que a complexidade industrial (Cl) não influenciou significativamente o nível de gerenciamento de resultados, tanto por módulo, quanto por accruals positivos e negativos. Infere-se assim, que empresas cujo faturamento é distribuído entre diversos setores não apresentaram práticas diferenciadas de GR em relação às demais empresas, cujo faturamento é concentrado em poucos ou em um único setor. 
Tabela 3

Resumo dos resultados das equações 2, 3 e 4 - Complexidade Industrial

\begin{tabular}{|c|c|c|c|}
\hline \multirow[b]{2}{*}{ Variáveis } & \multicolumn{2}{|c|}{ Coeficientes das Equações } & \multirow[b]{2}{*}{$\begin{array}{l}4 \\
\text { ADNJM } \\
\text { Fixo }\end{array}$} \\
\hline & $\begin{array}{l}2 \\
\text { ADMJM } \\
\text { Aleatório }\end{array}$ & $\begin{array}{l}3 \\
\text { ADPJM } \\
\text { Aleatório }\end{array}$ & \\
\hline \multicolumn{4}{|l|}{ Variável de Teste } \\
\hline $\mathrm{Cl}$ & $-0,001303$ & $-0,019826$ & $-0,0003411$ \\
\hline \multicolumn{4}{|l|}{ Variáveis de Controle } \\
\hline HÁ & 0,0010187 & $-0,005959$ & $-0,0023857$ \\
\hline$\vee V$ & $-0,000312$ & 0,0008216 & 0,0003012 \\
\hline $\mathrm{BF}$ & $-0,003083$ & 0,0171022 & 0,0075279 \\
\hline GC & 0,0107442 & 0,0316241 & 0 \\
\hline \multicolumn{4}{|c|}{ Resumo das Equações } \\
\hline Sig. Equação: & 0,5200 & 0,1076 & 0,1137 \\
\hline Chow: & $0,0000^{* * *}$ & $0,0000^{* * *}$ & $0,0000^{* * *}$ \\
\hline LM Breusch-Pagan: & $0,0000^{* * *}$ & $0,0000^{* * *}$ & $0,0000^{* * *}$ \\
\hline Hausman: & 0,3166 & 0,4547 & $0,0356^{* *}$ \\
\hline$R^{2}:$ & 0,0083 & 0,0243 & 0,0410 \\
\hline Nº observações: & 420 & 155 & 265 \\
\hline \multicolumn{4}{|c|}{$\begin{array}{l}\text { Legenda: ADMJM: Accruals Discricionários (AD) por módulo (M) do } \\
\text { ADPJM: Accruals Discricionários (AD) positivos (P) do Jones Modificadd } \\
\text { Discricionários (AD) negativos (N) do Jones Modificado (JM); Cl: com } \\
\text { honorários de auditoria; } V \mathrm{~V} \text { : volatilidade das vendas; BG: tipo de auc } \\
\text { corporativa. } \\
\text { Fonte: Elaborada pelos autores. } \\
\text { *** Significativo até } 1 \% ;{ }^{* *} \text { Significativo até } 5 \% ;{ }^{*} \text { Significativo até } 10 \% ; \\
\text { Fonte: Dados da pesquisa. }\end{array}$} \\
\hline
\end{tabular}

Na Tabela 4 apresenta-se a influência da complexidade do negócio na prática oportunista dos gestores, por meio das equações 5, 6 e 7.

Observa-se na Tabela supracitada que o $R^{2}$ apresentou valores de 0,0057; 0,0219 e 0,0430, respectivamente, para as três equações. A equação 13 (Sig. Equação: 0,0984) demonstrou-se significativa a 10\%. A variável de controle honorários de auditoria (HA) demonstrou significância para a diminuição da prática oportunista de gestores. 
Tabela 4

Resumo dos resultados das equações 5, 6 e 7 - Complexidade do Negócio

\begin{tabular}{|c|c|c|c|}
\hline \multirow[b]{2}{*}{ Variáveis } & \multicolumn{3}{|c|}{ Coeficientes das Equações } \\
\hline & $\begin{array}{l}5 \\
\text { ADMJM } \\
\text { Aleatório }\end{array}$ & $\begin{array}{l}6 \\
\text { ADPJM } \\
\text { Aleatório }\end{array}$ & $\begin{array}{l}7 \\
\text { ADNJM } \\
\text { Fixo }\end{array}$ \\
\hline \multicolumn{4}{|l|}{ Variável de Teste } \\
\hline $\mathrm{CN}$ & 0,0010909 & $-0,002800$ & $-0,0026387$ \\
\hline \multicolumn{4}{|l|}{ Variáveis de Controle } \\
\hline HÁ & 0,0009885 & $-0,005951$ & $-0,0023129^{* *}$ \\
\hline VV & $-0,000323$ & 0,0008242 & 0,0003075 \\
\hline $\mathrm{BF}$ & $-0,003229$ & 0,0172619 & 0,0071613 \\
\hline GC & 0,0104402 & 0,0307744 & 0 \\
\hline \multicolumn{4}{|c|}{ Resumo das Equações } \\
\hline Sig. Equação: & 0,5067 & 0,1124 & $0,0984^{*}$ \\
\hline Chow: & $0,0000^{* * *}$ & $0,0000^{* * *}$ & $0,0000^{* * *}$ \\
\hline LM Breusch-Pagan: & $0,0000^{* * *}$ & $0,0000^{* * *}$ & $0,0000^{* * *}$ \\
\hline Hausman: & 0,2401 & 0,4598 & $0,0219^{* *}$ \\
\hline$R^{2}:$ & 0,0057 & 0,0219 & 0,0430 \\
\hline № observações: & 420 & 155 & 265 \\
\hline \multicolumn{4}{|c|}{$\begin{array}{l}\text { Legenda: ADMJM: Accruals Discricionários (AD) por módulo (M) do Jones Modificado (JM); } \\
\text { ADPJM: Accruals Discricionários (AD) positivos (P) do Jones Modificado (JM); ADNJM: Accruals } \\
\text { Discricionários (AD) negativos (N) do Jones Modificado (JM); CN: complexidade do negócio; } \\
\text { HA: honorários de auditoria; VV: volatilidade das vendas; BG: tipo de auditoria; GC: } \\
\text { governança corporativa. } \\
\text { Fonte: Slaborificada pelos autores. }\end{array}$} \\
\hline
\end{tabular}

Na Tabela 5 apresentam-se os resultados das equações de 8, 9 e 10, as quais têm por intuito verificar a influência das medidas de complexidade organizacional no GR. 
Tabela 5

Resumo dos resultados das equações 8, 9 e 10 - Complexidade Organizacional

\begin{tabular}{|c|c|c|c|}
\hline \multirow[b]{2}{*}{ Variáveis } & \multicolumn{3}{|c|}{ Coeficientes das Equações } \\
\hline & $\begin{array}{l}8 \\
\text { ADMJM } \\
\text { Aleatório }\end{array}$ & $\begin{array}{l}9 \\
\text { ADPJM } \\
\text { Fixo }\end{array}$ & $\begin{array}{l}10 \\
\text { ADNJM } \\
\text { Aleatório }\end{array}$ \\
\hline \multicolumn{4}{|l|}{ Variáveis de Teste } \\
\hline SUB & $-0,000116$ & $-0,000606$ & 0,0000675 \\
\hline AA & $0,000482 *$ & $0,015130^{* * *}$ & 0,0000638 \\
\hline TAM & $-0,01316^{* *}$ & $-0,10339^{* * *}$ & $0,0101291^{* * *}$ \\
\hline ROE & $-0,000187$ & $0,001610^{* *}$ & $0,0006498^{* * *}$ \\
\hline DLP & $-0,003304$ & 0,0050232 & $-0,0102214^{* * *}$ \\
\hline $\mathrm{EC}$ & 0,0035747 & $-0,003117$ & 0,0021022 \\
\hline \multicolumn{4}{|l|}{ Variáveis de Controle } \\
\hline $\mathrm{HA}$ & 0,0012364 & $-0,00574^{* *}$ & $-0,0019501^{* *}$ \\
\hline VV & $-0,000029$ & $0,001884^{* * *}$ & 0,0001754 \\
\hline $\mathrm{BF}$ & 0,0002686 & $-0,019004$ & 0,0092966 \\
\hline GC & 0,021067 & 0 & 0,005995 \\
\hline \multicolumn{4}{|c|}{ Resumo das Equações } \\
\hline Sig. Equação: & $0,0055^{* * *}$ & $0,0003^{* * *}$ & $0,0015^{* * *}$ \\
\hline Chow: & $0,0000^{* * *}$ & $0,0000^{* * *}$ & $0,0000^{* * *}$ \\
\hline LM Breusch-Pagan: & $0,0000^{* * *}$ & $0,0000 * * *$ & $0,0000^{* * *}$ \\
\hline Hausman: & 0,0541 & 0,0060 & $-7,22$ \\
\hline$R^{2}:$ & 0,0785 & 0,2908 & 0,1636 \\
\hline No observações: & 420 & 155 & 265 \\
\hline
\end{tabular}

Legenda: ADMJM: Accruals Discricionários (AD) por módulo (M) do Jones Modificado (JM): ADPJM: Accruals Discricionários (AD) positivos (P) do Jones Modificado (JM); ADNJM: Accruals Discricionários ( $A D$ ) negativos (N) do Jones Modificado (JM); SUB: quantidade de subsidiárias; AA: anos de atuação; TAM: tamanho da empresa; ROE: rentabilidade do patrimônio líquido; DLP: dívidas de longo prazo; EC: capital de terreiros na estrutura de capital; HA: honorários de auditoria; VV: volatilidade das vendas; BG: tipo de auditoria; GC: governança corporativa. *** Significativo até $1 \%$; ${ }^{* *}$ Significativo até $5 \%$; * Significativo até $10 \%$;

Fonte: Elaborada pelos autores.

$O R^{2}$ das equações demonstrou-se a 0,0785 (Equação 8), 0,2908 (Equação 9) e 0,1636 (Equação 10). Em relação à significância das equações, todas se mostraram significativas a 5\% (Equação 8 - Sig. Equação: 0,0055; Equação 9 - Sig. Equação: 0,0003 e. Equação 10: 0,0015). Em se tratando da significância das variáveis, observou-se com base nas equações, que as medidas de complexidade organizacional influenciaram significativamente o nível de gerenciamento de resultados das empresas brasileiras analisadas. O tempo de atuação da empresa no mercado (AA) influenciou no aumento da prática oportunista dos gestores, tanto nos accruals por módulo (Equação 8), quanto nos positivos (Equação 9). As dívidas de longo prazo (DLP) apresentaram influência negativa (Equação 10) no nível de gerenciamento de resultados por accruals negativos. A rentabilidade do patrimônio líquido (ROE) teve efeito para o aumento do gerenciamento de resultados, por accruals positivos (Equação 9) e negativos (Equação 10). O tamanho da empresa (TAM) demonstrou efeito no aumento do nível de gerenciamento de resultados por accruals negativos (Equação 10), e diminuição do gerenciamento de resultados por accruals por módulo (Equação 8) e positivo (Equação 9), demonstrando, desta forma, 
resultado não conclusivo. Recomenda-se em pesquisas futuras o aprofundamento da análise sobre o efeito do tamanho das empresas (TAM) no nível de gerenciamento de resultados das empresas.

Quanto à significância das variáveis de controle, observou-se que a volatilidade das vendas (VV) apresentou efeito para o aumento do nível de gerenciamento de resultados por accruals positivos (Equação 9), enquanto os honorários de auditoria (HA) demonstraram influência para a diminuição do nível de GR, por accruals negativos (Equação 10) e positivos (Equação 9). Na Tabela 6 apresenta-se o resumo das equações 11, 12 e 13, as quais têm por intuito verificar o efeito da complexidade total no nível de GR.

\section{Tabela 6}

Resumo dos resultados das equações 11, 12 e 13 - Complexidade Total

\begin{tabular}{|c|c|c|c|}
\hline \multirow[b]{2}{*}{ Variáveis } & \multicolumn{3}{|c|}{ Coeficientes das Equações } \\
\hline & $\begin{array}{l}11 \\
\text { ADMJM } \\
\text { Aleatório }\end{array}$ & $\begin{array}{l}12 \\
\text { ADPJM } \\
\text { Aleatório }\end{array}$ & $\begin{array}{l}13 \\
\text { ADNJM } \\
\text { Aleatório }\end{array}$ \\
\hline \multicolumn{4}{|l|}{ Variável de Teste } \\
\hline CT & $-0,300370$ & $-2,41166^{* *}$ & $-0,3984522 *$ \\
\hline \multicolumn{4}{|c|}{ Variáveis de Controle } \\
\hline $\mathrm{HA}$ & 0,0010976 & $-0,00525^{* *}$ & $-0,0015547$ \\
\hline $\mathrm{VV}$ & $-0,000222$ & $0,001143^{*}$ & $0,0005147^{* * *}$ \\
\hline $\mathrm{BF}$ & $-0,003175$ & 0,0185463 & 0,012281 \\
\hline GC & 0,0100462 & 0,0196311 & 0,0081429 \\
\hline \multicolumn{4}{|c|}{ Resumo das Equações } \\
\hline Sig. Equação: & 0,4125 & $0,0174^{* *}$ & $0,0305^{* *}$ \\
\hline Chow: & $0,0000^{* * *}$ & $0,0000^{* * *}$ & $0,0000^{* * *}$ \\
\hline LM Breusch-Pagan: & $0,0000^{* * *}$ & $0,0000^{* * *}$ & $0,0000^{* * *}$ \\
\hline Hausman: & 0,5652 & 0,5913 & $0,0001^{* * *}$ \\
\hline$R^{2}:$ & 0,0114 & 0,0736 & 0,0635 \\
\hline Nºbservações: & 420 & 155 & 265 \\
\hline
\end{tabular}

Legenda: ADMJM: Accruals Discricionários (AD) por módulo (M) do Jones Modificado (JM); ADPJM: Accruals Discricionários (AD) positivos (P) do Jones Modificado (JM); ADNJM: Accruals Discricionários (AD) negativos (N) do Jones Modificado (JM); CT: complexidade total; HA: honorários de auditoria; VV: volatilidade das vendas; BG: tipo de auditoria; GC: governança corporativa.

*** Significativo até $1 \%$; ** Significativo até $5 \%$; Significativo até $10 \%$;

Fonte: Elaborada pelos autores.

Conforme apresentado na Tabela 6, o coeficiente de explicação da Equação 11 foi de 1,14\%, da Equação 12 de 7,36\% e da Equação 13 de 6,35\%. As equações 12 e 13 apresentaram-se significativas a 10\% (Equação 12 - Sig. Equação: 0,0174; Equação 13 - Sig. Equação: 0,0305). Em relação às variáveis significativas das equações, constatou-se que a complexidade total (CT) influenciou significativamente a diminuição do nível de gerenciamento de resultados, por accruals positivos (Equação 12) e negativos (Equação 13). Em relação às variáveis de controle, observou-se que a volatilidade das vendas (VV) apresentou influência para o aumento do nível de gerenciamento de resultados, por accruals positivos (Equação 12) e negativos (Equação 13). Os honorários de auditoria demonstraram influência negativa nos accruals positivos (Equação 12). 


\subsection{Análise de Sensibilidade dos Resultados}

Para a análise de sensibilidade dos dados utilizou-se do Modelo KS (Equação 14), que abrange um conjunto diferenciado de informações apresentados pelo Modelo Jones Modificado (utilizado como principal modelo de análise), contribuindo para a verificação de outros resultados, que porventura possam ocorrer. Utilizou-se dos resíduos do Modelo KS (por módulo, positivos e negativos) das empresas analisadas, como variáveis dependentes em novas regressões de dados em painel, a fim de se observar a influência da complexidade industrial, do negócio, organizacional e total no nível de gerenciamento de resultados. Por questão de espaço, os resultados desta análise de sensibilidade não estão apresentados em tabela.

Com base nesta análise de sensibilidade (KS), contataram-se algumas inconsistências das variáveis significativas com os resultados verificados pelo modelo principal de análise (Jones Modificado), como por exemplo, a influência da variável complexidade do negócio (CN) e tipo de auditoria (BF), que não foi observado nas equações anteriores, influência negativa da variável tamanho da empresa (TAM), bem como a influência contrária dos honorários de auditoria (HA). Por outro lado, observaram-se semelhanças como da variável quantidade de anos de atuação das empresas (AA), a qual aumentou o GR.

Cabe ressaltar que os achados da presente pesquisa resultantes do Modelo Jones Modificado devem ser encarados com parcimônia, uma vez que se alternando o modelo de análise de GR para o KS, algumas variáveis explicativas podem demonstrar resultados diferenciados. De todo o modo, observa-se que somente a variável de honorários de auditoria apresentou relação contrária com - GR quando analisado por KS, em relação ao Jones Modificado. Os demais resultados da análise de sensibilidade foram complementares em relação aos achados utilizando-se do Modelo Jones Modificado.

Há diferentes modelos para se verificar o gerenciamento de resultados das empresas, cada modelo avalia um conjunto específico de informações. O Modelo Jones Modificado e o Modelo KS utilizam diferentes informações para avaliar a prática oportunista dos gestores, o que pode explicar as diferenças nos resultados. De todo o modo, utiliza-se na presente pesquisa, para as considerações finais do estudo, os resultados decorrentes do Modelo Jones Modificado, uma vez que, de acordo com Dechow et al. (1995), este possui maior poder de detecção do gerenciamento de resultados dentre os verificados na literatura.

\subsection{Discussão dos Resultados}

Diante dos resultados verificados pelas Equações 2 a 13, apresenta-se a refutação ou não das hipóteses de pesquisa. Em relação ao resultado observado de que nas empresas brasileiras analisadas a complexidade industrial não influenciou o nível de gerenciamento de resultados, devido a não significância da variável, rejeitou-se a hipótese $\mathrm{H}_{1}$ : quanto maior o grau de complexidade industrial, maior a prática de gerenciamento de resultados das empresas. 
Assim, observou-se que os gestores das empresas não utilizaram da maior complexidade da organização para agir oportunisticamente, seja em benefício próprio ou em benefício da empresa. As empresas analisadas com receita segmentada proporcionalmente em vários segmentos não demonstraram ter práticas diferenciadas de GR, daquelas que apresentaram maior proporção de receita em poucos segmentos. Infere-se, desta forma, a não observância de assimetria da informação (GR) quando da participação de empresas em vários segmentos principais (segmentos que geram receitas semelhantes), ou seja, por mais que haja participação em diversos segmentos relevantes, as empresas não têm demonstrado práticas diferenciadas de GR. Este achado vai de encontro aos resultados verificados por Farooqi et al. (2014), os quais observaram que a complexidade industrial impactou no aumento do nível de gerenciamento de resultados. Por outro lado, estão em congruência com o estudo de Barinov et al. (2014), os quais também não verificaram relação significativa entre a complexidade industrial e a assimetria da informação.

A hipótese $\mathrm{H}_{2}$ : quanto maior o grau de complexidade do negócio, maior a prática de gerenciamento de resultados das empresas foi rejeitada devido a não significância desta variável. Constatou-se que as empresas analisadas que apresentaram complexidade do negócio não se mostraram associadas significativamente ao nível de gerenciamento.

Este achado vai ao encontro dos resultados de Jennings e Tanlu (2014), os quais também não observaram relação significativa entre a complexidade do negócio e a assimetria da informação. Entretanto, não converge com os resultados de Demirkan et al. (2012) e Barinov et al. (2014), que preconizaram que a complexidade do negócio aumentaria a assimetria da informação. No entanto, esses autores analisaram a influência da complexidade do negócio na assimetria da informação pela ótica do gerenciamento de resultados, com modelos não analisados nesta pesquisa, tais como Dechow e Dichev (2002), Cohen et al. (2008) e Cohen e Zarowin (2010). Infere-se, assim, que a refutação da hipótese $\mathrm{H}_{2}$ pode ter sido ocasionada também em função das contas utilizadas para o cálculo do accruals discricionários, diferente das analisadas nos estudos anteriores.

Ainda com base na análise de sensibilidade do presente estudo, observouse influência significativa da complexidade do negócio, entretanto, para a diminuição do nível de gerenciamento de resultados, ou seja, contrário ao preconizado pela literatura (Demirkan et al., 2012; Barinov et al., 2014). Uma justificativa para este resultado é que as empresas brasileiras analisadas apresentaram média baixa de setores (apenas 2), diferentemente do apresentado pelos estudos anteriores. Desse modo, é possível que tais atividades não chegaram a comprometer a qualidade da informação contábil no mercado brasileiro.

A hipótese $\mathrm{H}_{3}$ : as medidas de complexidade organizacional apresentam influência significativa na prática de gerenciamento de resultados das empresas foi rejeitada, visto que nem todas as medidas de complexidade organizacional apresentaram-se significativas e com o sinal esperado. As medidas de complexidade organizacional rentabilidade do patrimônio líquido e tempo de atuação da empresa no mercado influenciaram no aumento da prática oportunista dos gestores. Por outro lado, as dívidas de longo prazo apresentaram influência na diminuição da prática oportunista dos gestores. Em relação à literatura, quanto aos achados sobre a rentabilidade do patrimônio líquido e 
dívidas de longo prazo, estes corroboram estudos de autores como: Baptista (2008) e Hail e Leuz (2009). Entretanto, o resultado sobre tempo de atuação da empresa no mercado vai de encontro ao verificado por Chichernea et al. (2012). As demais medidas de complexidade organizacional não demonstraram influência significativa com $O$ nível de GR ou demonstraram resultados inconclusivos.

Devido a não influência significativa das medidas de complexidade organizacional quantidade de subsidiárias e estrutura de capital no gerenciamento de resultados, rejeitaram-se as hipóteses $\mathrm{H}_{3 a}$ : quanto maior a quantidade de subsidiárias, maior a prática de gerenciamento de resultados das empresas; $\mathrm{H}_{3 \mathrm{f}}$ : quanto maior a concentração de capital de terceiros na estrutura de capital, menor a prática de gerenciamento de resultados das empresas. Também, considerando os resultados inconclusivos da medida de complexidade organizacional tamanho da empresa, rejeitou-se a hipótese $\mathrm{H}_{3 c}$ : quanto maior $\mathrm{O}$ tamanho, menor a prática de gerenciamento de resultados das empresas.

Depreende-se, assim, que a ramificação das empresas analisadas em subsidiárias não comprometeu a simetria informacional entre a empresa sede e suas subsidiárias, o que vai de encontro aos resultados de Hill e Jones (1992), Roth e O'Donnell (1996). Estes autores preconizaram que empresas diversificadas se preocupam com as contas consolidadas, ofuscando a eficiência das informações das subsidiárias, o que compromete a simetria da informação. Assim, sob o aspecto do GR, não se observou relação significativa entre a quantidade de subsidiárias das empresas analisadas e a assimetria da informação.

Da mesma forma, observou-se que a concentração de capital de terceiros na estrutura de capital das empresas também não se associou com práticas diferenciadas de GR, o que vai de encontrado ao preconizado por Hail e Leuz (2009), que apontaram que as empresas, a fim de conseguirem recursos a custos mais baixos, quando da utilização de capital de terceiros, reportam qualidade da informação contábil aos agentes econômicos, o que poderia ser observado pela redução do GR. Em relação ao tamanho das empresas analisadas, não se verificou indícios satisfatórios da influência no gerenciamento de resultados, o que sugere o aprofundamento em estudos futuros, com análise de como esta influência ocorre. Estas evidências estão congruentes com o estudo de Farias (2012), o qual também não observou relação direta entre o tamanho da empresa e o reporting financeiro. De todo o modo, cabe ressaltar que na análise de sensibilidade, a variável tamanho da empresa demonstrou influência negativa no nível de gerenciamento de resultados, o que indica o cuidado de se analisar o gerenciamento de resultados, uma vez que dependendo do modelo, pode-se encontrar diferentes resultados.

A rentabilidade do patrimônio líquido demonstrou influência significativa e positiva no gerenciamento de resultados, aceitando-se, deste modo, a hipótese $\mathrm{H}_{3 \mathrm{~b}}$ : quanto maior a rentabilidade, maior a prática de gerenciamento de resultados das empresas. Conforme Baptista (2008), a fim de evitar decréscimo no nível de rentabilidade da empresa, os gestores gerenciam o resultado para aumentá-lo. Os investidores que possuem menor nível de informação sobre a empresa exigem maior retorno sobre o patrimônio líquido, a fim de diminuir a percepção de risco empresarial, o que leva os gestores a praticarem 0 gerenciamento de resultados (Easley \& O'hara, 2004). 
Verificou-se que quanto maior a experiência da empresa no mercado, medida pela quantidade de anos de atuação, maior a prática oportunista dos gestores, rejeitando-se, dessa forma, a hipótese $\mathrm{H}_{3 \mathrm{~d}}$ : quanto maior o tempo de atuação no mercado, menor a prática de gerenciamento de resultados das empresas.

Este achado vai de encontro aos resultados de Chichernea et al. (2012), para os quais, empresas com período longo de atuação no mercado possuem a tendência de estarem mais preparadas para a realização de estimativas, o que resultaria em melhor qualidade da informação contábil. Assim, constatou-se que as empresas brasileiras analisadas aproveitaram sua experiência e conhecimento no mercado para realizar práticas oportunistas e obter benefícios privados por meio do gerenciamento de resultados.

Observou-se que as empresas analisadas que apresentaram níveis elevados de dívidas de longo prazo demonstraram ter menor assimetria de informação em relação à prática oportunista dos gestores. Por tal motivo, aceitou-se a hipótese $\mathrm{H}_{3 \mathrm{e}}$ : quanto maior o saldo das dívidas de longo prazo, menor a prática de gerenciamento de resultados das empresas. Tal resultado pode estar fundamentado na preocupação das empresas endividadas de não aumentar a assimetria da informação, o que poderia reduzir a confiança dos credores.

Quanto à última hipótese de pesquisa, que tinha por intuito avaliar o efeito conjunto da complexidade industrial, do negócio e organizacional na prática de gerenciamento de resultados, observou-se que a proxy de complexidade total (que discrimina o efeito conjunto da complexidade industrial, do negócio e organizacional) demonstrou efeito significativo para a diminuição do nível de gerenciamento de resultados. Por tal motivo, aceitou-se a hipótese $\mathrm{H}_{4}$ : a existência conjunta de complexidade industrial, do negócio e organizacional implica em menores práticas de gerenciamento de resultados.

Este achado corrobora os resultados de Farooqi et al. (2014), os quais verificaram que empresas complexas globalmente sofrem menos problemas de agência do que empresas que apresentam alguma medida de complexidade de forma individualizada, visto que uma empresa complexa globalmente pode possuir mais mecanismos de controle do que uma empresa que começou a diversificar suas atividades.

Em relação às variáveis de controle, observou-se que a variável de honorário de auditoria impactou significativamente para a diminuição do nível de gerenciamento de resultados, porém, na análise de sensibilidade a relação foi positiva. De todo o modo, como a maioria das equações principais demonstraram relação negativa, infere-se que as empresas analisadas pagaram valores elevados de honorários de auditoria às firmas a fim de obterem serviços que diminuíssem problemas de agência. Empresas complexas, por possuírem transparência de informação limitada, influenciaram no aumento de assimetria informacional, que por sua vez, acarreta demanda por auditoria de alta qualidade. Empresas complexas organizacionalmente estão propensas a contratar auditoria de qualidade para diminuir custos de agência, reduzindo a assimetria da informação, pelo auxílio na asseguração da credibilidade das demonstrações financeiras (Liu \& Lai, 2012).

A variável volatilidade das vendas impactou significativamente para 0 aumento do nível de gerenciamento de resultados. De acordo com Bushman et 
al. (2004), a qualidade dos lucros é explicada em parte pela volatilidade dos retornos. A alta volatilidade das vendas associou-se com menor qualidade dos lucros, pois provoca erros de estimação, ocasionado por ambiente instável (Doyle et al., 2007).

As variáveis de governança corporativa e Big Four não demonstraram associação significativa com o nível de gerenciamento de resultados, com exceção da variável Big Four na análise de sensibilidade. Esse resultado pode ser explicado pela composição da amostra, que apresentou cerca de $90 \%$ das empresas auditadas por Bir Four e cerca de 74\% listadas em algum nível de GC da B3, o que limita o poder explicativo dessas variáveis sobre o GR.

\section{CONSIDERAÇÕES FINAIS}

Este estudo teve por objetivo analisar o efeito da complexidade empresarial na prática de gerenciamento de resultados. Para tal, foram utilizadas técnicas estatísticas para o tratamento dos dados, como regressão linear múltipla, estatística descritiva, entropia da informação, método TOPSIS e regressão de dados em painel. A amostra compreendeu 110 empresas listadas na B3, as quais possuíam todas as informações necessárias para a realização do estudo. 0 período de análise correspondeu aos anos de 2010 a 2013.

Com base nos resultados, observou-se que as empresas analisadas gerenciaram seus resultados, tanto para aumentá-lo, quanto para diminuí-lo. Quanto à dimensão de complexidade industrial, verificou-se que as empresas da amostra complexas industrialmente não se mostraram associadas as práticas oportunistas dos seus gestores. Desse modo, conclui-se que os gestores das empresas brasileiras analisadas cujas vendas estão distribuídas por diversos segmentos não aproveitaram a maior dificuldade de se monitorar tais atividades para gerenciar os resultados, seja em benefício próprio ou em benefício da própria empresa. Este achado pode representar que as empresas complexas industrialmente adotam mecanismos de monitoramento que mitigam práticas oportunistas dos gestores, ou que essas empresas estejam sujeitas a maior monitoramento externo, o que reduziria a oportunidade de tal prática.

Em relação à dimensão complexidade do negócio, também não se observou efeito significativo para o aumento da prática oportunista dos gestores. As empresas brasileiras analisadas apresentaram, em média, dois setores de atuação, o que pode ser considerado um nível relativamente baixo de complexidade do negócio, se comparado ao observado em estudos internacionais. Este fator pode ter contribuído para que a complexidade do negócio não tenha sido associada ao aumento das práticas de gerenciamento de resultados. Infere-se, assim, que a influência da complexidade do negócio nas práticas de GR pode variar dependendo do nível de segmentação das empresas em análise, o que justificaria os resultados contraditórios presentes na literatura. Os modelos para capturar as práticas de gerenciamento de resultados também podem influenciar esses resultados.

A respeito da dimensão complexidade organizacional, os efeitos distintos das diversas proxies de complexidade sobre as práticas de gerenciamento de resultados apresentados neste estudo reforçam a importância de se analisar a complexidade empresarial de modo mais amplo. Nesse sentido, observou-se que 
a complexidade total influenciou significativamente para a redução do nível de gerenciamento de resultados das empresas brasileiras analisadas. Portanto, depreende-se que as empresas que contrariaram o paradigma da simplicidade em suas atividades podem estar munindo-se de ferramentas para auxiliar na redução do GR.

Diante do exposto e respondendo ao problema de pesquisa, conclui-se que quando uma empresa atinge um nível elevado de complexidade total, que engloba todas as demais complexidades, seus mecanismos de governança, controle ou monitoramento, além de uma possível atenção externa, fazem com que elas procurem mitigar práticas oportunistas.

Estes achados constituem-se em evidências adicionais sobre os fatores influenciadores do gerenciamento de resultados, contribuindo com órgãos reguladores, auditores, preparadores das demonstrações contábeis e demais interessados na formulação de normas de governança e controles específicos para as empresas brasileiras, que possuem elevado tempo de atuação no mercado, rentabilidade do patrimônio líquido e volatilidade nas vendas.

Outra contribuição do presente estudo foi a criação de um índice de complexidade total, não presente em estudos anteriores, fornecendo novos insights sobre o efeito da complexidade empresarial no nível de GR no cenário de empresas brasileiras.

Apresentam-se como limitações do estudo os modelos para detectar o gerenciamento de resultados por meio de accruals discricionários, uma vez que estes podem apresentar vieses pela dificuldade de estimação da discricionariedade dos accruals. Outra limitação pode estar atrelada às medidas de complexidade utilizadas, visto que se poderia utilizar de outras medidas para avaliar a complexidade de empresas.

Ainda, cabe destacar que na análise não foi considerado o GR entre os níveis de governança corporativa, mas foi considerado a empresa como tendo governança corporativa, independentemente do nível. De acordo com Yeganeh et al. (2010), empresas que possuem níveis elevados de governança corporativa apresentam informações contábeis confiáveis e suficientes para os usuários. Assim, indica-se em estudos futuros a análise do GR entre os níveis de GC, a fim de avaliar se níveis mais elevados são mais atuantes para a diminuição do do GR. Todavia, depreende-se que tais limitações não invalidam ou tornam menos importantes os resultados encontrados neste estudo.

\section{REFERÊNCIAS}

Almeida, J. E. F. (2010). Qualidade da informação contábil em ambientes competitivos. 188 f. Tese (Doutorado em Ciências Contábeis) - Programa de Pós-Graduação em Ciências Contábeis, Departamento de Contabilidade e Atuária, Faculdade de Economia, Administração e Contabilidade, Universidade de São Paulo, São Paulo.

Anderson, P. (1999). Perspective: Complexity theory and organization science. Organization Science, 10 (3), 216-232. 
Brasil, Bolsa e Balcão. B3: O resultado da combinação entre a BM\&FBovespa e a CETIP. Recuperado 17 de julho de 2018 em: http://www.b3.com.br/ptbr/.

Baptista, E. M. B. (2008). Análise do perfil das empresas brasileiras segundo o nível de gerenciamento de resultados. 303 f. Tese (Doutorado em Administração) Programa de Pós-Graduação em Administração, Universidade Federal do Rio Grande do Sul, Rio Grande do Sul.

Barinov, A., Park, S. S. \& Yildizhan, C. (2014). Firm Complexity and post-earningsannouncement drift. Terry College of Business University of Georgia, Available at SSRN 2360338.

Boone, A. L., Field, L. C., Karpoff, J. M. \& Raheja, C. G. (2007). The determinants of corporate board size and composition: an empirical analysis. Journal of Financial Economics, 85 (1), 66-101.

Bushman, R., Chen, Q., Engel, E. \& Smith, A. (2004). Financial accounting information, organizational complexity and corporate governance systems. Journal of Accounting and Economics, 37 (2), 167-201.

Cardinaels, E., Roodhooft, F. \& Warlop, L. (2004). Customer profitability analysis reports for resource allocation: the role of complex marketing environments. Abacus, 40 (2), 238-258.

Cetorelli, N. \& Goldberg, L. S. (2014). Measures of complexity of global banks. Economic Policy Review, 20 (2).

Chichernea, D. C., Holder, A. D. \& Wei, J. D. (2012). Connecting the dots: the accruals quality premium vs the value premium. Managerial Finance, 38 (12), 1106-1133.

Dechow, P. M., Sloan, R. G. \& Sweeney, A. P. (1995). Detecting earnings management. The Accounting Review, 193-225.

Dechow, P., Ge, W. \& Schrand, C. (2010). Understanding earnings quality: a review of the proxies, their determinants and their consequences. Journal of Accounting and Economics, 50 (2), 344-401.

Demirkan, S., Radhakrishnan, S. \& Urcan. O. (2012). Discretionary accruals quality, cost of capital, and diversification. Journal of Accounting, Auditing \& Finance, 27 (4), 496-526.

Denis, D. J., Denis, D. K. \& Sarin, A. (1997). Agency problems, equity ownership, and corporate diversification. The Journal of Finance, 52(1), 135-160.

Doyle, J. T., Ge, W. \& Mcvay, S. (2007). Accruals quality and internal control over financial reporting. The Accounting Review, 82 (5), 1141-1170.

Easley, D. \& O'Hara, M. (2004). Information and the cost of capital. The Journal of Finance, 59 (4), 1553-1583. 
Fama, E. F. \& Jensen, M. C. (1983). Separation of ownership and control. Journal of Law and Economics, 301-325.

Farias, K. T. R. (2012). Mecanismos de controle do reporting financeiro das companhias abertas do Brasil. 204 f. Tese (Doutorado em Contabilidade) Departamento de Contabilidade e Atuária da Faculdade de Economia, Administração e Contabilidade, Universidade de São Paulo.

Farooqi, J., Harris, O. \& Ngo, T. (2014). Corporate diversification, real activities manipulation, and firm value. Journal of Multinational Financial Management, $27,130-151$.

Hail, L. \& Leuz, C. (2009). Cost of capital effects and changes in growth expectations around US cross-listings. Journal of Financial Economics, 93 (3), 428-454.

Healy, P. M. \& Wahlen, J. (1999). M. A review of earnings management literature and its implications for standard setting. Accounting Horizons, 13, 365-383.

Hill, C. W. L \& Jones, T. M. (1992). Stakeholder-agency theory. Journal of Management Studies, 29 (2), 131-154.

Hoitash, R. \& Hoitash, U. (2014). Measuring accounting disclosure complexity with XBRL. Working Paper, A vailable at SSRN 2433677.

Hou, K. \& Robinson, D. T. (2006). Industry concentration and average stock returns. The Journal of Finance, 61 (4), 1927-1956.

Jennings, J. \& Tanlu, L. (2014). The effect of organizational complexity on earnings forecasting behavior. Working paper, Washington University in St. Lovis.

Jiraporn, P., Kim, Y. S., Davidson, W. N. \& Singh, M. (2006). Corporate governance, shareholder rights and firm diversification: An empirical analysis. Journal of Banking \& Finance, 30 (3), 947-963.

Jones, J. J. (1991). Earnings management during import relief investigations. Journal of Accounting Research, 193-228.

Kang, S.-H. \& Sivaramakrishnan, K. (1995). Issues in testing earnings management and an instrumental variable approach. Journal of Accounting Research, 353367.

Leuz, C. (2003). IAS versus US GAAP: information asymmetry-based evidence from Germany's new market. Journal of Accounting Research, 41 (3), 445-472.

Linck, J. S., Netter, J. M. \& Yang, T. (2008). The Determinants of Board Structure. Journal of Financial Economics, 87, 308-328. 
Liu, C.-L. \& Lai, S.-M. (2012). Organizational complexity and auditor quality. Corporate Governance: An International Review, 20 (4), 352-368.

Lopes, A. B. (2009). The relation between firm-specific corporate governance, cross-listing and the informativeness of accounting numbers in Brazil. $236 \mathrm{f}$. Thesis (Doctor of Philosophy) - in the Faculty of Humanities, The University of Manchester.

Martin, J. D. \& Sayrak, A. (2003). Corporate diversification and shareholder value: a survey of recent literature. Journal of Corporate Finance, 9 (1), 37-57.

Martinez, A. L. (2008). Detectando earnings management no Brasil: estimando os accruals discricionários. Revista de Contabilidade \& Finanças, 19 (46), 7-17.

Martinez, A. L. (2006). Minimizando a variabilidade dos resultados contábeis: estudo empírico do income smoothing no Brasil. Revista Universo Contábil, 2 (1), 09-25.

Mcnichols, M. F. (2000). Research design issues in earnings management studies. Journal of Accounting and Public Policy, 19 (4), 313-345.

Muketha, G. M., Ghani, A. A. A., Selamat, M. H. \& Atan, R. (2010). A survey of business process complexity metrics. Information Technology Journal, v. 9, n. 7, p. 1336-1344.

Ramanujam, V. \& Varadarajan, P. (1989). Research on corporate diversification: A synthesis. Strategic Management Journal, 10 (6), 523-551.

Roth, K. \& O'Donnell, S. (1996). Foreign subsidiary compensation strategy: An agency theory perspective. Academy of Management Journal, 39 (3), 678703.

Santos, I. C. \& Rodrigues, F. S. S. (2007). Tempo, espaço e as organizações. Revista Brasileira de Gestão e Desenvolvimento Regional, 3 (2).

Schipper, K. (1989). Commentary on earnings management. Accounting Horizons, $3(4), 91-102$.

Thomas, J. \& Zhang, X.-J. (2000). Identifying unexpected accruals: a comparison of current approaches. Journal of Accounting and Public Policy, 19 (4), 347376.

Yeganeh, Y. H., Dadashi, I. \& Akbari, M. A. (2010). The relationship between auditor's opinions, corporate governance and accounting information quality. Corporate Governance and Accounting Information Quality, 14. 